\title{
PENGEMBANGAN KAMUS PEMELAJAR BAHASA INDONESIA BAGI PENUTUR ASING TINGKAT DASAR DI UNIVERSITAS MUHAMMADIYAH JAKARTA
}

\author{
Ahmad Fadly \\ Program Studi Pendidikan Bahasa dan Sastra Indonesia, Fakultas Ilmu Pendidikan, \\ Universitas Muhammadiyah Jakarta \\ ahmadfadly2901@gmail.com
}

\section{ABSTRAK}

Pengenalan kosakata dalam pengajaran Bahasa Indonesia bagi Penutur Asing (BIPA)Tingkat Dasar seringkali menghadapi kendala meski upaya itu penting sebagai landasan pengajaran pada tingkat selanjutnya. Kendala itu, yang juga dihadapi oleh di lembaga BIPA Universitas Muhammadiyah Jakarta, terutama berkaitan dengan ketiadaan kamus khusus pemelajar BIPA. Untuk itu, pengembangan kamus pemelajar BIPA merupakan suatu keniscayaan. Dengan pengumpulan korpus dan pendefinisian yang tepat, pengembangan kamus itu memudahkan pemelajar BIPA, khususnya tingkat dasar, untuk berkomunikasi dalam kebutuhan sintas. Selain itu, uji validasi oleh ahli dan uji coba oleh pengguna semakin menyempurnakan kamus tersebut. Pengembangan kamus itu diharapkan bermanfaat, baik bagi pemelajar BIPA maupun pengajar BIPA dalam mengenalkan kosakata yang sarat dengan kekayaan budaya Indonesia.

Kata kunci: kamus pemelajar, BIPA, Tingkat Dasar

\section{PENDAHULUAN}

$\mathrm{S}$ ebagaimana pemerolehan bahasa yang bertahap, pengajaran Bahasa Indonesia bagi Penutur Asing (BIPA) idealnya dilaksanakan secara berjenjang, mulai dari tingkat dasar sampai tingkat mahir atau lanjut. Pengajaran pada tingkat dasar menjadi titik tolak bagi pengajaran pada tingkat selanjutnya. Dengan demikian, pengajaran yang baik pada tingkat dasar menjadi landasan yang kukuh sehingga sangat menentukan keberhasilan pengajaran dan juga kemampuan pemelajar pada tingkat-tingkat selanjutnya.

Dalam mengajarkan BIPA di tingkat dasar, pengajar perlu lebih memperkenalkan kosakata kepada pemelajar BIPA daripada menekankan mereka dengan penguasaan tata bahasa. 
Sebab, pengenalan kosakata itu menjadi "kunci pembuka" pemahaman budaya Indonesia, mengingat bahwa dalam kosakata tercermin kekayaan budaya. Urgensi penguasaan kosakata itu sesuai dengan pandangan Wilkins: . . "without grammar very little can be conveyed, without vocabulary nothing can be conveyed" (Alfaki, 2015). Meskipun demikian, para pemelajar BIPA seringkali dihadapkan pada perbedaan konteks budaya dan alat ungkapnya (kosakata) sehingga mengalami kesulitan dalam menghafalkan dan memahami kosakata Indonesia.

\section{Di Universitas Muhammadiyah} Jakarta (UMJ), mahasiswa asing pada umumnya mendapatkan nilai rendah pada hampir setiap mata kuliah. Kondisi itu tidak semata-mata disebabkan oleh rendahnya kapasitas intelektual mereka, tetapi karena lemahnya kemampuan berbahasa Indonesia mereka. Meskipun telah didirikan lembaga BIPA UMJ sejak 2017, pemelajarannya masih belum optimal. Penyebab utamanya ialah belum adanya kamus pemelajar BIPA. Akibatnya, mereka mengandalkan Kamus Besar Bahasa Indonesia (KBBI) versi daring (online) untuk mencari padanan atau definisi kata. Padahal, KBBI memiliki struktur lema dan sublema yang besar, sedangkan mayoritas lema (dan sublema) itu belum diperlukan oleh pemelajar BIPA, khususnya tingkat dasar. Di samping itu, pendefinisian lema (dan sublema) dalam KBBI seringkali menggunakan klausa kompleks sehingga sulit dipahami oleh pemelajar BIPA. Oleh sebab itu, mereka mengalami kesulitan dalam menghafalkan dan memahami kosakata dalam kamus tersebut.

Untuk mengatasinya, diperlukan kamus khusus pemelajar BIPA yang dapat dijadikan sebagai sarana pengenalan kosakata. Dalam penyusunannya, kamus pemelajar itu haruslah didasarkan pada korpus linguistik yang dihimpun berdasarkan teks terkini. Cara itu dilakukan, mengingat bahwa bahasa bersifat dinamis sehingga makna kosakata pun disesuaikan dengan penggunaannya terkini.

Penelitian yang mengandalkan korpus linguistik telah dilakukan beberapa peneliti. Pelbagai penelitian itu tidak terbatas pada penyusunan dan pengembangan kamus, melainkan juga penelitian wacana (analisis wacana kritis). Pada 2017 Sakhiyya mengkaji identitas sosial pada penelitiannya yang berjudul Negotiating Social Identity Through Questions In Casual Conversations: A Critical Discourse Analysis. Ia menggunakan percakapan sebagai datanya. Pada tahun yang sama, Al Fajri meneliti wacana hegemoni dan minoritas seputar imigran yang berlandaskan korpus pada penelitiannya yang bertajuk Hegemonic And Minority Discourses Around Immigrants: A Corpus-Based Critical Discourse Analysis. Kedua penelitian tersebut memiliki keunggulan bahwa konteks kebahasaannya lebih relevan dengan realitas kekinian sehingga tidak diragukan aktualitasnya.

Atas dasar itulah penelitian ini mengandalkan korpus linguistik dan berupaya menjawab permasalahan mengenai cara membangun korpus linguistik, cara menyusun kamus pemelajar BIPA Tingkat Dasar berbasis korpus, dan pengembangannya.

Kamus, sebagaimana didefinisikan oleh Zgusta berarti kumpulan bentuk linguistik yang disusun berdasarkan penggunaan bahasa masyarakat yang dimaknai oleh penyusun agar pengguna memahaminya 
(Sterkenburg, 2003). Karya leksikografis itu dipandang sebagai buku acuan yang disusun untuk menyediakan informasi linguistik seperti pelafalan, pengejaan, makna leksikal, etimologi, pelbagai aspek penggunaan bahasa, dan/atau informasi ensiklopedis (seperti biografi, geografi, fakta sejarah, konsep keilmuan dan taksonomi), dan lain sebagainya. Sementara itu, kamus pemelajar didesain khusus bagi kebutuhan praktis pengajaran oleh guru dan pemelajar bahasa. (Hartmann, 2001). Seiring dengan dinamika bahasa, kamus idealnya direvisi secara berkala. Bahkan penyusunannya didasarkan pada korpus linguistik, mengikuti dinamika tersebut.

Selain dipandang sebagai kumpulan teks (baik lisan ataupun tulisan) yang terbaca oleh komputer dan variatif serta mencerminkan penggunaan bahasa lisan dan tulis (Stubbs, 2001; Sinclair, 2004), korpus juga dipilih berdasarkan kriteria eksternal untuk mewakili suatu bahasa atau variasi bahasa, sebagai sumber data untuk penelitian linguistik. (Sinclair, 2004: 13).

Dalam pengumpulan korpus perlu dipertimbangkan pelbagai aspek: keaslian (autenticity), aspek representasi, aspek ketercakupan, aspek kecocokan, aspek preskriptif, aspek sosial, aspek waktu, aspek geografis, dan aspek bahasa teknik (Setiawan, 2015). Untuk mengumpulkan korpus, peneliti menggunakan perangkat lunak AntConc, sedangkan dalam penyusunan kamus ia memanfaatkan perangkat lunak Lexique Pro.

Adapun dalam mendefinisikan lema, peneliti ini menggunakan teori yang ditawarkan oleh Riemer (2010), yaitu Genus dan Differentia. Teori itu relevan dengan pengguna kamus (pemelajar BIPA Tingkat Dasar) sebab definisi yang ditawarkan menjadi sederhana dan mudah dipahami.

\section{METODE PENELITIAN}

Denelitian ini dilaksanakan di Lembaga - Bahasa Indonesia bagi Penutur Asing (BIPA) Universitas Muhammadiyah Jakarta. Adapun waktu penelitiannya adalah dari Januari 2018 s.d. September 2018.

Dalam membangun korpus, peneliti ini mula-mula mencari sumber data tertulis yang berkaitan dengan BIPA. Sumber data itu ialah buku ajar BIPA yang diterbitkan oleh Badan Pengembangan dan Pembinaan Bahasa, Kementerian Pendidikan dan Kebudayaan, yang berjudul Sahabatku Indonesia. Selain itu, peneliti ini juga mengumpulkan pelbagai tulisan, baik fiksi maupun nonfiksi yang tersedia di internet dalam rentang 2016-awal 2018.

Data tersebut dijadikan sebagai korpus dengan mengonversinya dari MS Word 2007 ke dalam bentuk Text Document (*txt). Setelah itu, peneliti ini memasukkannya ke dalam perangkat lunak (software) AntConc 3.4.4w untuk mengidentifikasi konkordansi dan kolokasinya. Ia menggunakan AntConc versi $4.3 .3 \mathrm{w}$ karena versi itulah yang sesuai dengan program komputer yang dimiliki oleh peneliti (Windows). 
Tampilan AntConc 4.3.3w dapat dilihat sebagai berikut.

\section{HASIL DAN PEMBAHASAN}

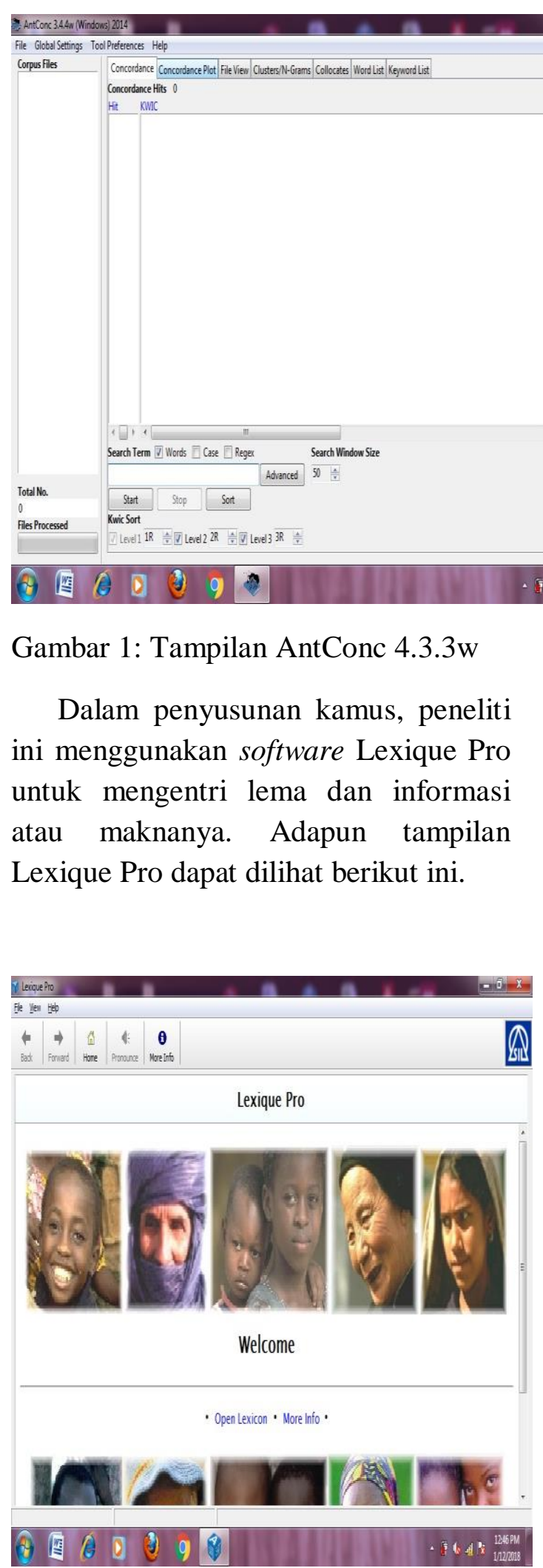

enelitian ini menghasilkan sebuah 1 media pembelajaran bahasa Indonesia berupa kamus pemelajar BIPA. Produk itu disusun berdasarkan korpus yang bersumber dari cerita pendek yang diterbitkan di koran dan buku ajar BIPA tingkat dasar. Setelah disusun, produk tersebut diuji validitasnya oleh dua ahli pengajaran BIPA dan dua pengguna produk itu (pengajar dan pemelajar BIPA UMJ). Ahli pengajaran BIPA bertindak menilai dan memberi saran mengenai rancangan pembuatan kamus yang dibuat commeliputi: (1) Aspek tipe lema, (2) 12Pendefinisian, (3) Kelugasan,

Keterbacaan, dan (5) Kesesuaian dengan tingkat kemampuan pemelajar BIPA.

a) Validasi Produk Oleh Ahli Pengajaran BIPA

1) Aspek Tipe Lema

Aspek ini berupa kata masukan dalam kamus di luar definisi atau penjelas lain yang diberikan dalam entri pada kamus. Hasil penilaian dari ahli diperoleh hasil penilaian yang tinggi.

\section{2) Aspek Pendefinisian}

Aspek definisi yaitu pemberian (deskripsi) atau penjelas yang membatasi makna kata. Tipe definisi yang menggunakan tipe definisi genus dan differentiae ini diperoleh hasil penilaian yang tinggi.

Gambar 2: Tampilan Lexique Pro 
3) Aspek Kelugasan

Kamus idealnya menggunakan definisi yang lugas, terlebih kamus pemelajar BIPA. Aspek kelugasan ini menghasilkan nilai yang cukup tinggi.

\section{4) Aspek Keterbacaan}

Aspek keterbacaan ini meliputi penggunaan kaidah bahasa yang terdapat pada pendefinisian kamus. Dalam aspek keterbacaan, hasil yang diperoleh adalah sangat tinggi.

5) Aspek Kesesuaian dengan tingkat pemelajar

Berdasarkan aspek ini peneliti akan mengetahui kesesuaian tingkat perkembangan pemahaman pemelajar. Penilaian ahli pada aspek kesesuaian tingkat pemahaman pemelajar BIPA menghasilkan nilai yang tergolong sangat tinggi.

\section{6) Aspek Secara Keseluruhan}

Secara keseluruhan, penilaian ahli menghasilkan penilaian kamus yang baik dan dianggap layak berdasarkan kriteria penilaian yang telah ditetapkan sebelumnya.

Setelah dilakukan validasi, peneliti melakukan perbaikan dan penyempurnaan kamus pemelajar BIPA Tingkat Dasar berdasarkan validator ahli. Tidak semua aspek mendapatkan catatan dari validator ahli. Meskipun demikian, catatan validator berkelindan dengan dua aspek. Aspek pendefinisian terkait dengan tidak konsistennya beberapa definisi dengan Teori Genus dan Differentiae. Ini berdampak pada keterbacaan yang menurun.

Setelah diperbaiki berdasarkan masukan dan catatan ahli, peneliti mengujicobakannya kepada dua pengguna, yaitu pengajar dan pemelajar BIPA UMJ. Pada tahap ini peneliti membagikan angket yang harus diisi oleh pengajar dan pemelajar untuk menilai kelayakan dari produk yang telah dibuat.

Adapun hasil penilaian angket pada uji coba tersebut.

a) Uji coba oleh pengajar BIPA

\section{1) Aspek Tipe Definisi Lema}

Aspek ini bertujuan untuk memberi penjelas tentang suatu kata, di setiap entri lema, agar pemelajar dapat memahami. Adapun tanggapannya tergolong dalam kriteria sangat tinggi.

\section{2) Aspek Keterbacaan}

Aspek ini bertujuan untuk memahami penggunaan kaidah bahasa yang terdapat pada pendefinisian kamus pemelajar BIPA Tingkat Dasar. Tanggapannya tergolong ke dalam penilaian yang sangat tinggi.

\section{3) Aspek Pilihan Kata}

Aspek ini bertujuan untuk pemelajar agar dapat memahami kaidah penggunaan bahasa yang tepat pada pendefinisian kamus tanpa salah makna. Tanggapannya tergolong ke dalam kriteria penilaian sangat tinggi.

4) Aspek tampilan menarik

Aspek ini bertujuan untuk pemelajar menilai tampilan yang terdapat pada kamus pemelajar BIPA dengan adanya pewarnaan dan perwajahan (layout) yang dapat 
memfasilitasi pemelajar sehingga menarik dalam penggunaannya. Tanggapannya tergolong ke dalam kriteria penilaian sangat tinggi.

\section{5) Aspek Kemanfaatan}

Aspek ini bertujuan untuk pemelajar menilai seberapa manfaatnya kamus ini dalam pemelajaran BIPA. Tanggapannya tergolong ke dalam kriteria penilaian cukup tinggi.

\section{6) Aspek Penyajian Materi}

Aspek ini bertujuan untuk menekankan pada bagaimana isi dari materi yang ditampilkan untuk dapat diterima pemelajar dalam mempelajari materi bahasa Indonesia. Responsnya tergolong ke dalam kriteria penilaian sangat tinggi.

Secara umum, kamus pemelajar BIPA Tingkat Dasar ini dianggap layak berdasarkan kriteria penilaian yang telah ditetapkan sebelumnya. Adapun kekurangan berupa inkonsistensi pendefinisian dan keterbacaan telah diperbaiki berdasarkan masukan dari validator dan pengguna.

\section{KESIMPULAN}

$\mathcal{B}$ erdasarkan hasil penelitian dan pengembangan kamus pemelajar BIPA dengan menggunakan aplikasi AntConc dan Lexique Pro dapat secara efektif memudahkan pemelajar BIPA dalam mengenal kosakata dan memahami budaya yang terkandung dalam kosakata dasar.

Uji validasi dari ahli pengajaran BIPA dan pengguna (pengajar dan pemelajar BIPA) menunjukkan bahwa kamus yang dikembangkan layak untuk dijadikan sebagai media pengajaran BIPA, khususnya tingkat dasar.

Saran untuk peneliti selanjutnya yang akan melanjutkan penelitian mengenai pengembangan kamus sebaiknya:

1. Memanfaatkan korpus linguistik agar mencerminkan penggunaan bahasa yang alamiah sehingga relevan dengan kebutuhan kekinian.

2. Memperbanyak referensi mengenai kamus pemelajar BIPA, khususnya tata cara dan prosesnya sehingga penelitian dapat berjalan lebih baik dan lancar.

3. Pada peneliti selanjutnya agar menjalankan proses penelitian pengembangan kamus pemelajar BIPA secara benar dan teratur agar produk berkualitas dan dapat dikembangkan secara massal.

\section{UCAPAN TERIMA KASIH}

Deneliti mengucapkan terima kasih 1 kepada Lembaga Penelitian dan Pengabdian kepada Masyarakat Universitas Muhammadiyah Jakarta yang telah memberikan dukungan, baik moril maupun meteriil kepada peneliti dalam melakukan penelitian ini.

\section{REFERENSI}

Al Fajri, Muchamad Sholakhuddin. "Hegemonic and Minority Discourses Around Immigrants: A Corpus-Based Critical Discourse Analysis" dalam International Journal on Applied Linguistics, Vol 7 No 2 September 2017. 
Alfaki, Ibrahim Mohamed. "Vocabulary Input in English Language Teaching: Assessing The Vocabulary Load in Spine Five" dalam International Journal of English Language and Linguistics Research, Vol. 3, No. 1, Januari 2015.

Atkins, B.T Sue. dan Michael Rundell. 2008. The Oxford Guide to Practical Lexicography. New York: Oxford University Press.

Hartmann, R. R. K. 2001. Teaching and Researching Lexicography. Edinburgh: Pearson Education Limited.

Hizbullah dkk. 2014. Penyusunan Model Korpus Al-Qur'an Digital. Jurnal ALAzhar Indonesia Seri Humaniora. Vol .3 , No. 3 .

Prihantoro. 2016. "Survei Program Pengolah Korpus untuk Data Bahasa Indonesia dan Bahasa Derah di Indonesia". Prosiding Seminar Leksikografi Indonesia. Badan Pengembangan dan Pembinaan Bahasa.

Riemer, Nick. 2010. Introducing Semantics. Cambridge University Press.

Riduwan. 2015. Belajar Mudah Penelitian Untuk Guru-Karyawan dan Peneliti Pemula. Bandung: Alfabeta.
Sakhiyya, Zulfa. "Negotiating Social Identity Through Questions In Casual Conversations: A Critical Discourse Analysis" dalam International Journal on Applied Linguistics, Vol 6 No 2 September 2017.

Setiawan, Teguh. 2015. Leksikografi. Yogyakarta: Ombak.

Sinclair, J. 2004. Trust The Text: Language, corpus and discourse. London: Routledge.

Sugiyono. 2016. “Tantangan Leksikografis Bahasa-Bahasa Daerah di Indonesia". Prosiding Seminar Leksikografi Indonesia. Badan Pengembangan dan Pembinaan Bahasa

Stubbs, Michael. 2001. "Computer-assisted Text and Corpus Analysis: Lexical Cohesion and Communicative Competence" dalam The Handbook of Discourse Analysis. Deborah Schiffrin, Deborah Tannen, dan Heidi E. Hamilton (Eds) Blackwell Publisher Inc. Massachussetts.

Van Sterkenburg, Piet. 2003. A Practical Guide to Lexicography. Amsterdam: John Benjamins Publishing Co. 
